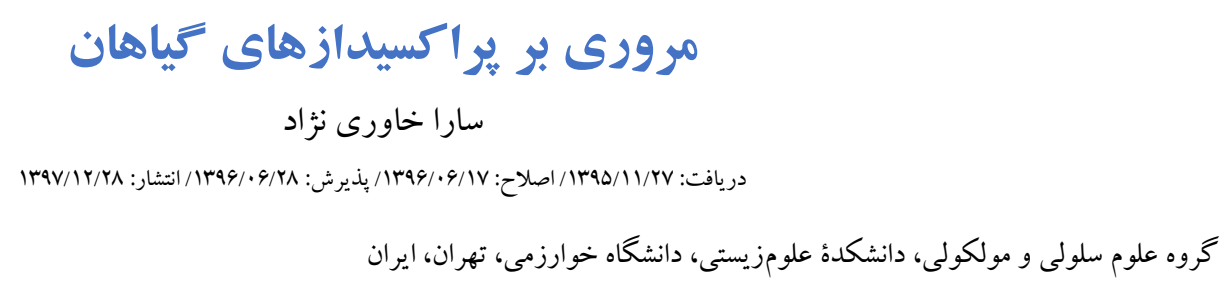

مسئول مكاتبات: Khavari-Nejad@khu.ac.ir

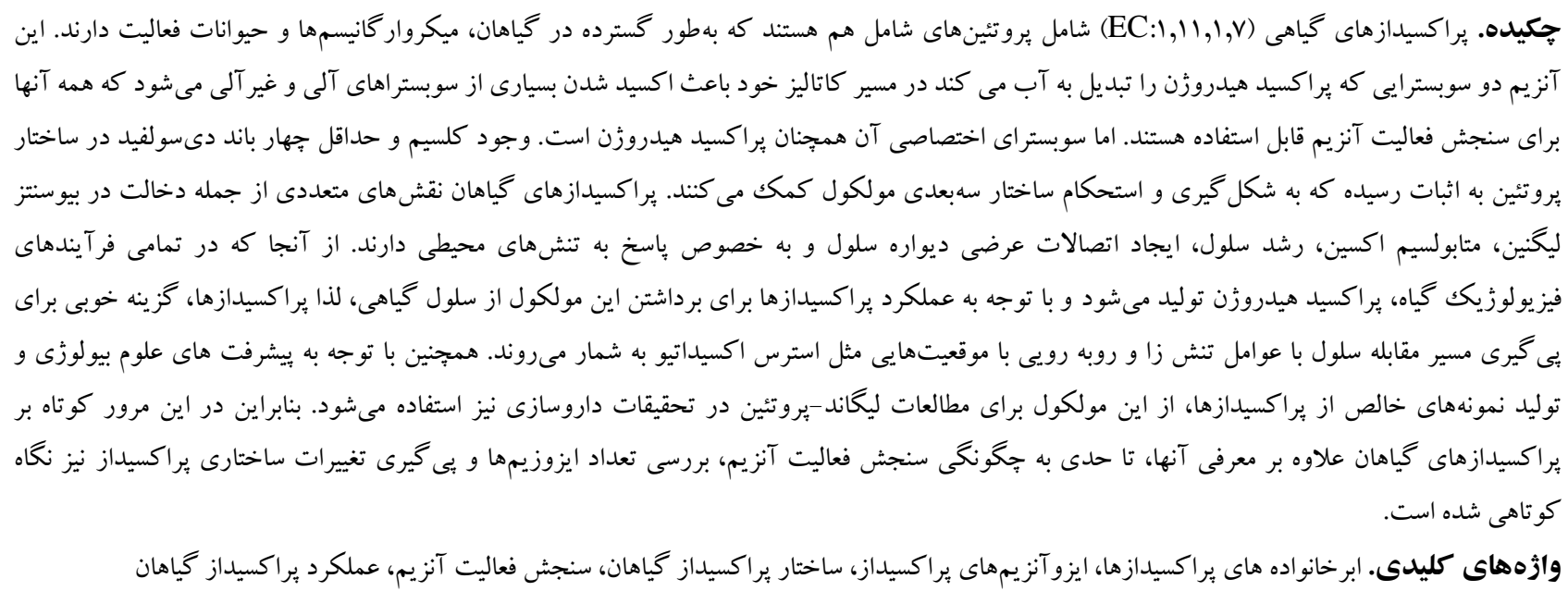

\title{
A review on plant peroxidases
}

Sarah Khavari-Nejad

Received 15.02.2017/ Revised 08.09.2017/ Accepted 19.09.2017/ Published 19.03.2019

Department of Cell and Molecular Sciences, Faculty of Biological Sciences, Kharazmi University, Tehran, Iran Correspondent author: Khavari-Nejad@khu.ac.ir

Abstract. Plant peroxidases (EC: 1.11.1.7) are heme-containing proteins widely found in plants, microorganisms and
animals. This two-substrate enzyme catalyzes the hydrogen peroxide into water by oxidation of many organic and
inorganic substrates, all of which can be used to measure enzyme activity. Nevertheless, its specific substrate is
hydrogen peroxide. The presence of Calcium and at least four disulfide bonds in the protein structure contributes to the
formation and strength of the three-dimensional structure of the molecule. Plant peroxidase plays roles in the lignin
biosynthesis, auxin metabolism, cell growth, cell wall cross-linking and in the response to environmental stresses.
Therefore, peroxidase is considered to be a good option in the monitoring of the way in which cells deal with stress
factors such as oxidative stress. Nowadays, according to the production of pure samples of this molecule, peroxidase is
used in ligand-protein studies in pharmaceutical research. In this brief overview, we have had a brief look at the way in
which enzyme activity is measured, the number of isoenzymes in a cell and the ensuing conformational changes of
peroxidase.

Keywords. assay the enzyme activity, conformation of plant peroxidase, function of plant peroxidase, peroxidase isoenzymes, peroxidase super families 
Aslic et al., 1997; Baunsgard et ( كربوهيدرات دارنــ

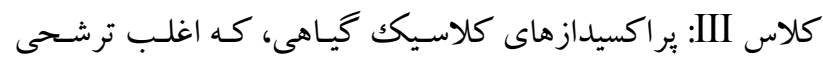

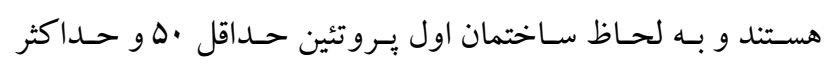

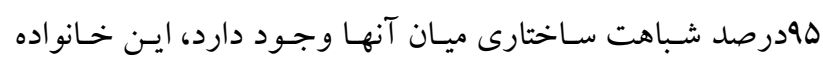

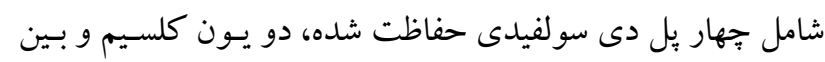

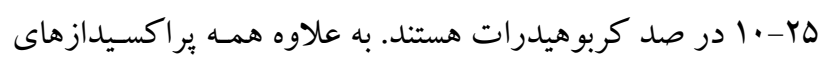

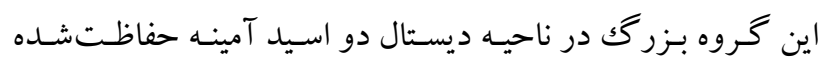

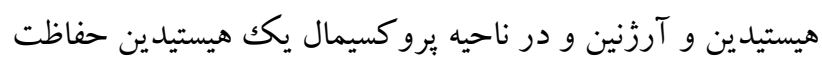

شده دارند (Gajhede et al., 1997). كلاس هاى I و III داراى يكك نياى مشتر كك باكتريايى هستـند كـه در كلاس I سكانس باكتريايى آن از همه لحاظ حفظ شـده امـا در

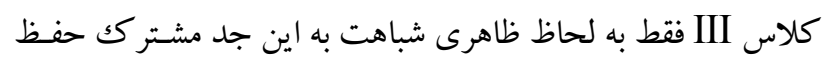
شده است (Schuller et al., 1996).

ساختمان و يايدارى

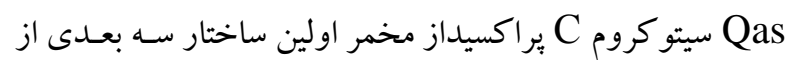

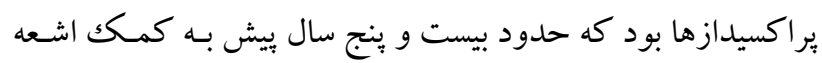

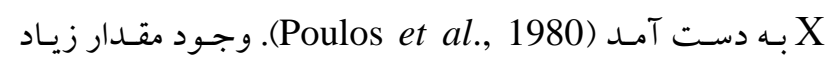

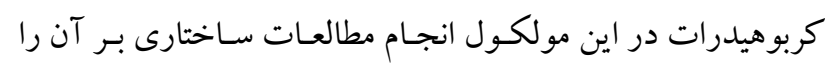

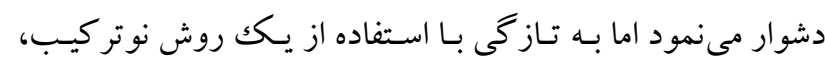

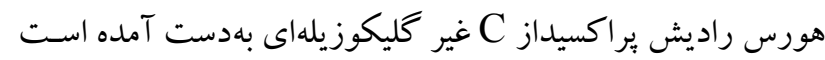

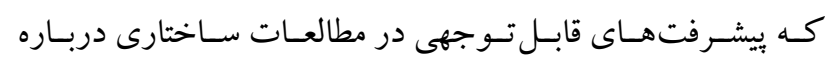

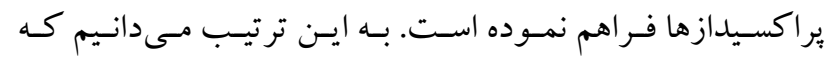

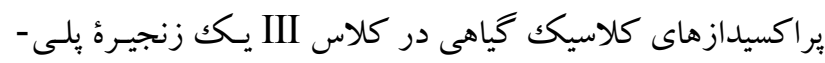

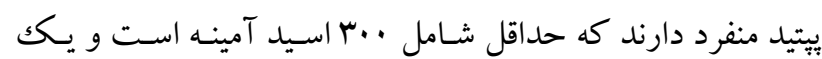

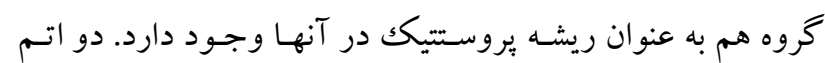

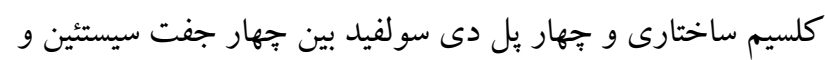
يكك بِ نمكى آسپارتات - آرزنين درساختار ديده مى شود و و بيشتر

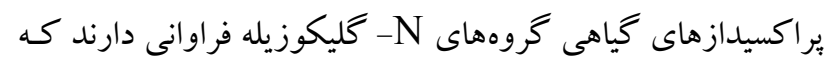

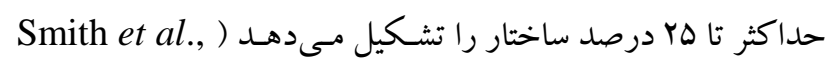

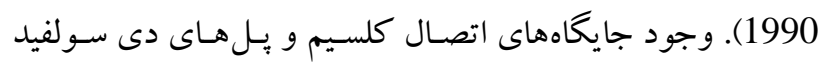

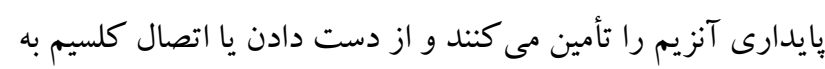

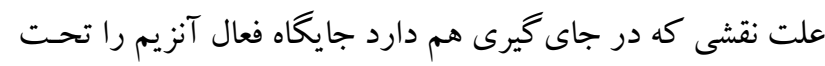

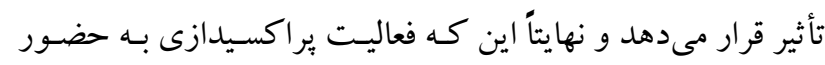

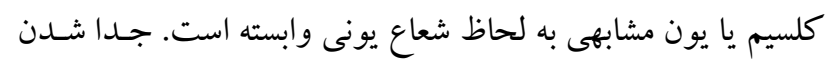

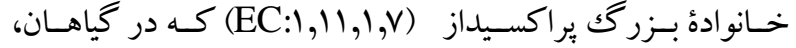

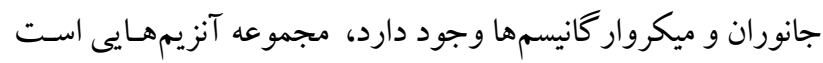

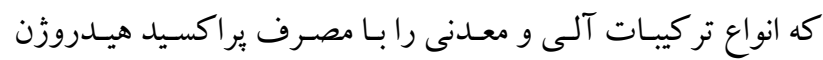

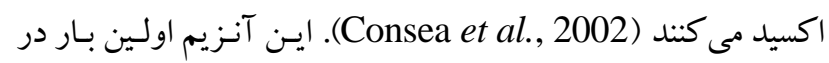

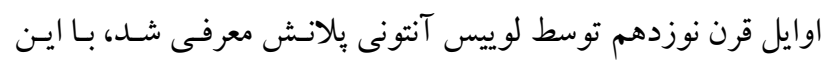

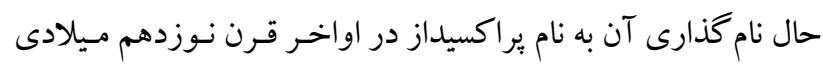

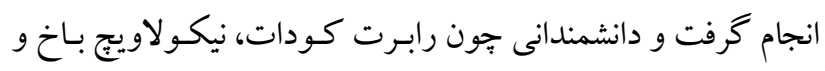

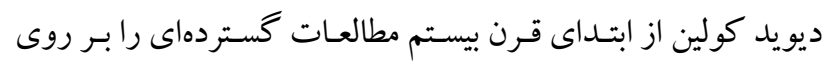

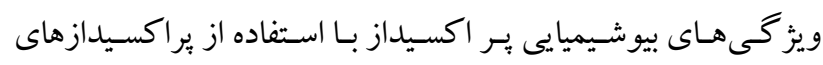

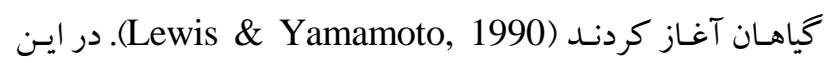

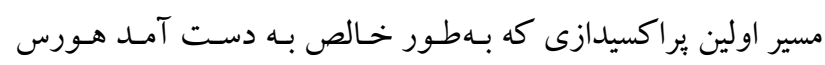

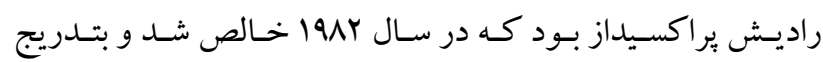

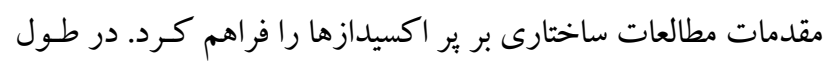

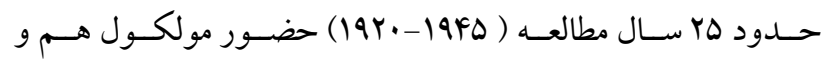

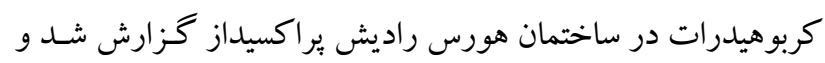

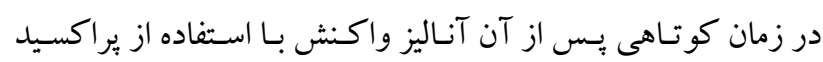

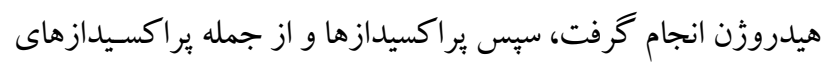

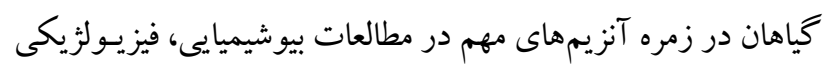
و داروسازى قرار گرفتند (Hiraga et al., 2001).

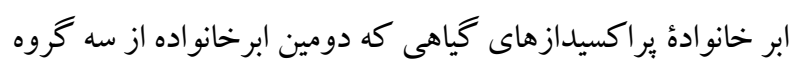

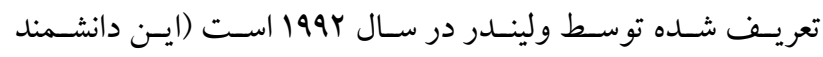

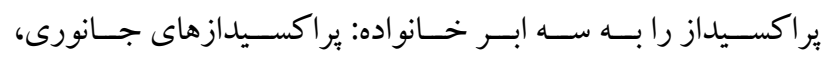

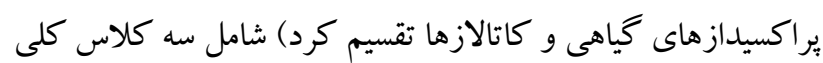
كـلاس I: براكسـيدازهاى بروكـاريوتى، كـه مهـم تـرين عضـو آن

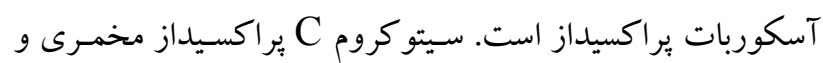

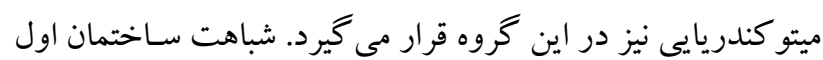

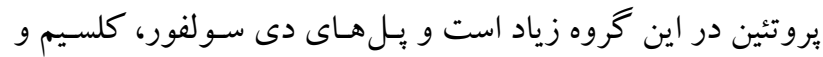

كربوهيدرات در ساختار آنها وجود ندارد (Dunford,1999).

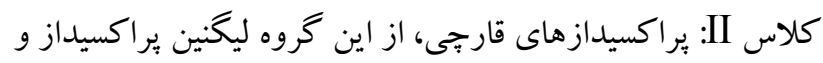

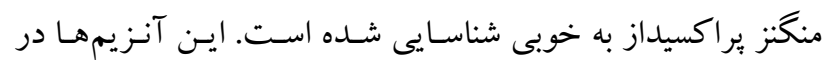

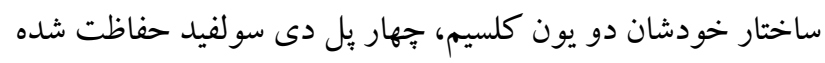


تبديل مىشود (در اين مرحله دومين تركيب حد واسط تشكيل مى -

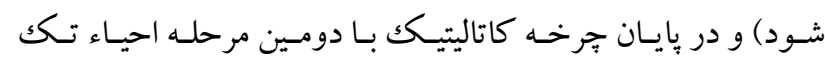

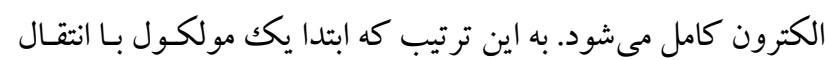
يكك الكترون به تر كيب حد واسط دوم تبديل به راديكال شده، نهايتاً

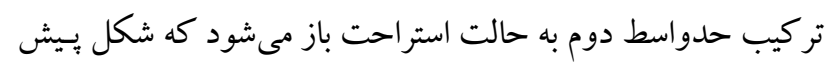

از شروع واكنش است (Hayashi \& Yamazaki, 1979).

$$
\begin{aligned}
& E\left(\mathrm{Fe}^{I I I}, \mathrm{P}\right)+\mathrm{H}_{2} \mathrm{O}_{2} \rightarrow E\left(\mathrm{Fe}_{\text {compoundI }}^{I V}=O, p^{0+}\right)+\mathrm{H}_{2} \mathrm{O} \\
& \text { تشكيل حدواسط اول } \\
& E\left(F e^{I V}=o, p^{o+}\right)+R H \rightarrow E\left(F e_{\text {compound }}^{I V}=o, p\right)+R^{0} \\
& \text { تشكيل حد واسط دوم } \\
& E\left(F^{I V}=o, p\right)+R H \rightarrow E\left(F e^{I I I}, p\right)+R^{0}+H_{2} O \\
& \text { باز }
\end{aligned}
$$

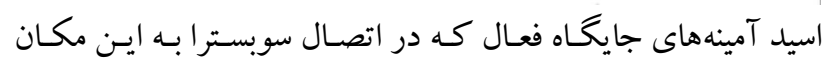

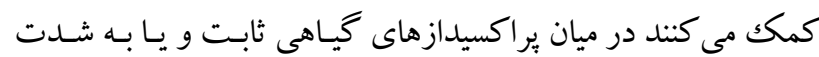

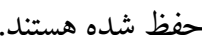

تركيبات بسيار متنوعى از جمله آمين هاى آروماتيكك، اينـدولهـا،

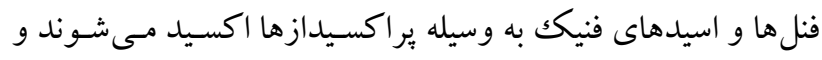

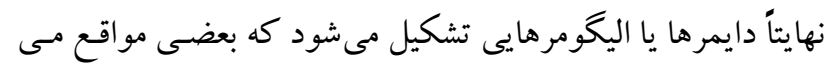
تو اند دوباره توسط ير اكسيدازها اكسيد شـود (Veitch, 2004).

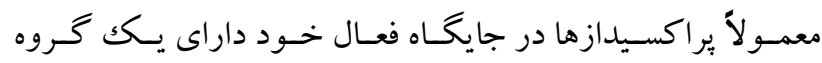

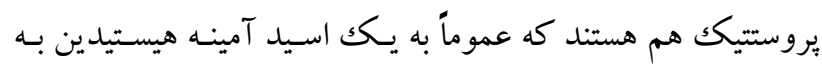

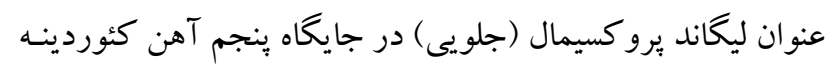

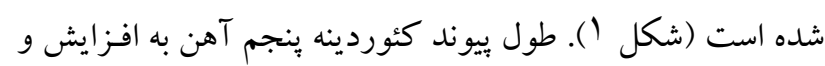

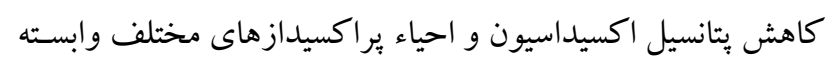

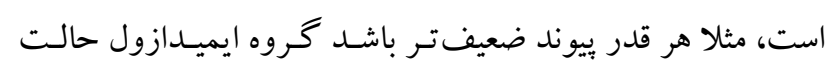

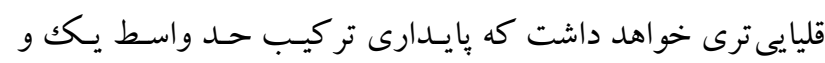

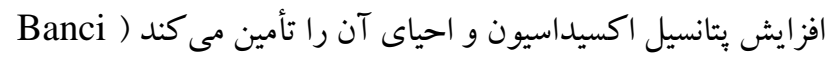
et al., 1991; Hayashi \& Yamazaki, 1979 هيستيدين از طريق بروتون خود با كربو كسيلات زنجيـره جانبى در

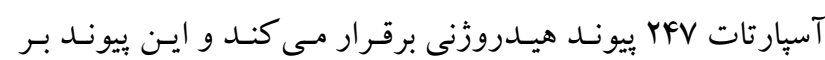

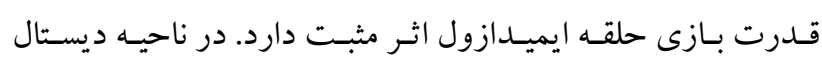

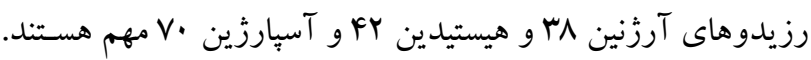

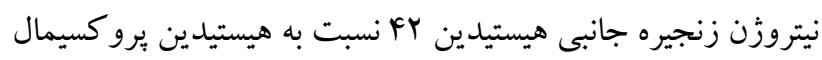

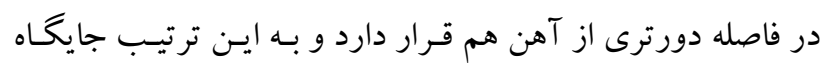

كلسيم به علت خارج كردن يروتئين از شـكل طبيعى تـاخوردگى -

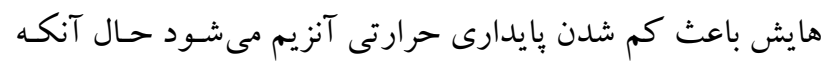

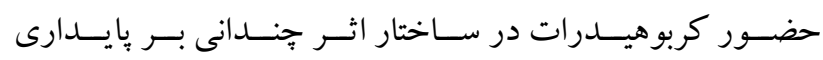

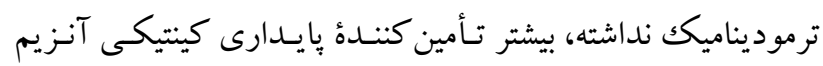

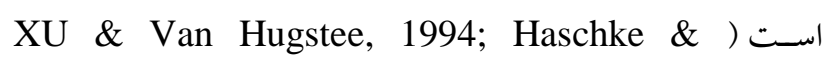
.(Friedhollf, 1987; Tmas \& Welinder, 1998 در موجـودات عـالى معمـولا بـيش از يـكك ايزوفـرم براكسـيداز وجود دارد كه عموما به لحاظ كاتاليتيك و ساختمان تفاوت دارند. براى مثال در برنج ها و در تنباكو rا ايزوزيم شناخته شده اسـت و

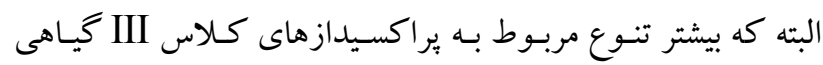
است. با اين وجود هنوز نقش بيولزيكك مستقل و مشخصى براى هر يكك از اين ايزوفرمها تعريف نشده است. برخى از اين ايزو آنزيمها در يكك بافت خاص و برخى ديخر در مرحله خاصى از مسـير رشـد

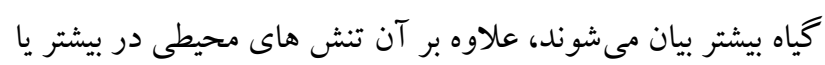
كم تر بيان شدن يكك ايزو آنزيم خاص نقش دارند. وجود اين همـه

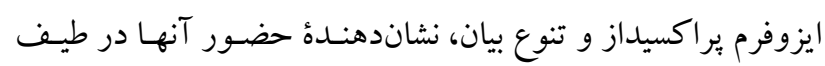

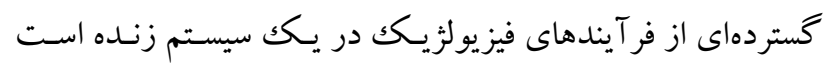

.(Gasper et al., 1985; Manjuanatha et al., 2003)

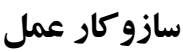

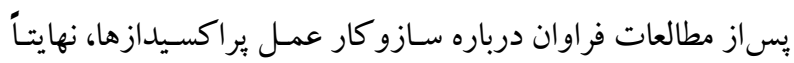

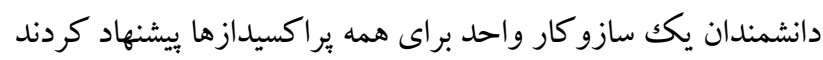
در: (Smith \& Veitch, 1998; Veitch \& Smith, 2001) اولين مرحله از اين مسير، بر اكسيد هيدروزن به عنوان ششمين ليكاند

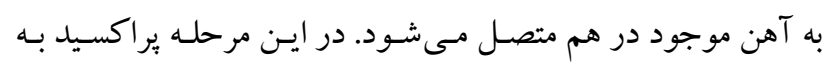

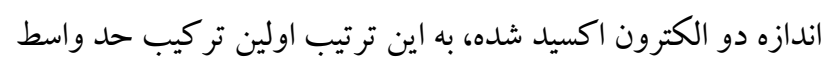

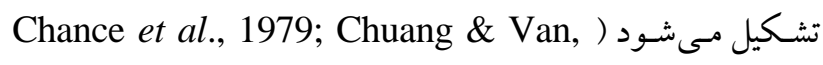
1992; Sivaraja et al., 1989

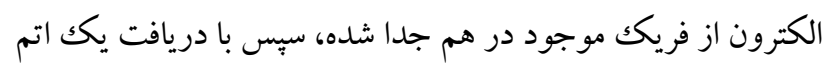

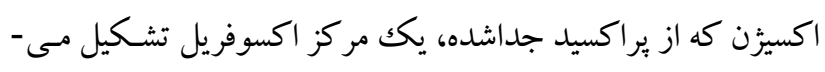

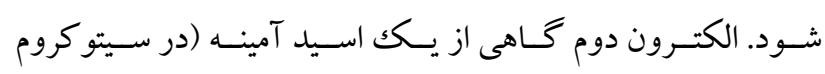
يراكسيداز) يا از يورفيرين (در هورس راديش براكسيداز) تأمين مى دئ-

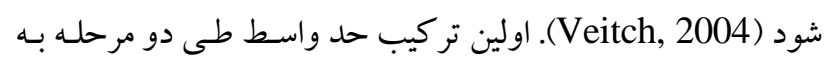
صورت تكك الكترونى احيا مىشود به اين صورت كه سوبستراى احيا

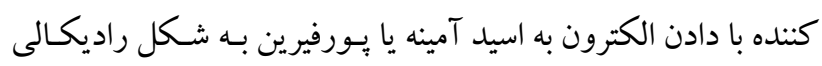




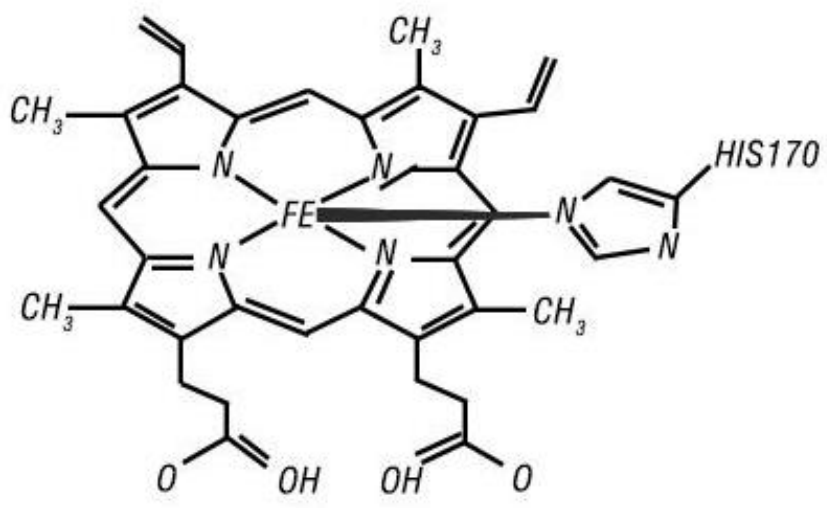

شكل 1- ريشه بروستتيك هم در براكسيدازها

Fig. 1. Heme in plant peroxidase

اما امروزه معلوم شده است كه سرعت كاتاليز براكسيدازى تنهـا بـه بتانسيل احياء سوبسـتر اي راديكـالى وابسته اسـت ( Candieas et al., 1997; Candieas et al., 1996; Job \& dunford, 1976). ير اكسيدازها به علت شركت در دو جرخهـ بر اكسـيداتيو و

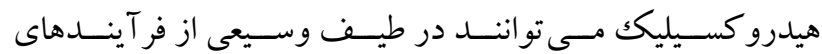
فيزيولزيك شركت كنند. به علاوه تنوع سوبستراهاى بر اكسيداز و توليد موادى جون ليخنـين و سـوبرين يـا كاتابوليسـم اكسـين دليـل قاطعى بر عملكرد غير قابـل جشـميوشى ايسن آنزيم در متابوليسـم

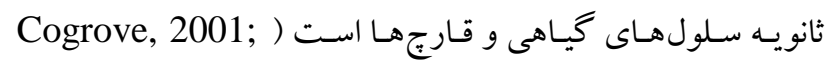
(Scialabba et al., 2002; Welinder, 1979 يراكسيدازها در طويل شدن سلولها و دفاع در مقابل ياتوزنهـا نيـز موثرند و بـه طـور كلى مجموعـه عملكـرد ير اكسـيدازها منجسر بـهـ تغييـرات فيزيولزيـك و تكـوينى كيـاه در طـول مسـير رشـد آن از جوانهزنى تا بيرى مىشود كه از جمله شامل موارد زير است: ا- رشد سلول و از بين رفتن ديواره سلولى، براكسيدازها بـا كنتـرل

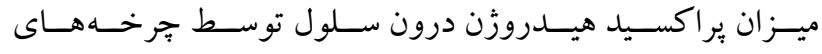
يراكسـيداتيو و هيدرو كسـيليكك مسـتقيما در فر آينــد رشـد سـلول شر كت مى كنند. راديكال HO كه توسط بر اكسيدازها توليد مى -

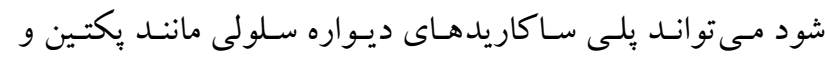

گزيلو كلو كان را برش دهد (Cogrove, 2001).

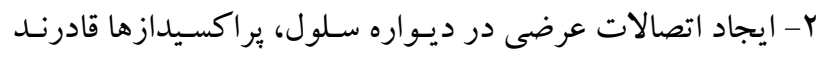
ميزان يراكسيد هيدروزن را در ديواره سلول كنتـرل كنتـد كـه ايـن
ششم كئوردينانس براى مولكولهايى جون سيانيد، آزايد و فلورايد كه به شكل بروتونه متصل مى شوند باز مى ماند. به علاوه يك بيوند هيدروزنى بين اكسيزّن كربونيل در زنجيسره جـانبى آسـبارزين •V و بروتون هيستيدين ديستال نيز وجود دارد كـهـ بـراى بايــارى مكـان Valderrama et al., 2002; Welinder \& ) فـال لازم اسـت (Gajhede, 1993

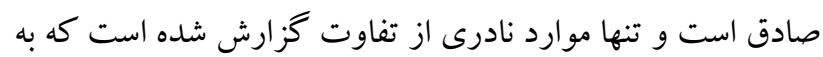

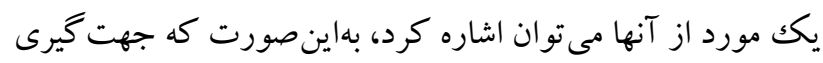

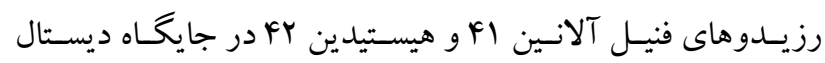
براكسيداز بادام زمينى و سويا كمى تغيير يافته است و اين تغييـر بـه علت جايكزينى يـك رزيـدوى آيزولوسين حجـيم در براكسيداز

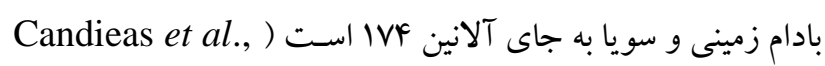
.(1996; Candieas et al., 1997

\section{واكنش و نقش يراكسيدازها}

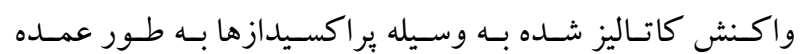
دهيدروزناسيون اكسيداتيو است كه به شكل زير نمايش داده مسى شود اما علاوه بر انتقال اكسيزئن تخريـب براكسـيد هيـدروزن نيـز انجام مى شود (Valderrama et al., 2002).

$$
\mathrm{H}_{2} \mathrm{O}_{2}+2 \mathrm{AH} 2 \rightarrow 2 \mathrm{H}_{2} \mathrm{O}+2 \mathrm{AH}^{0}
$$

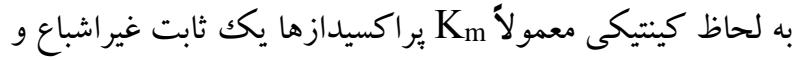
بنابر اين معمولا Km آنها بزرك است و كميلكس آنزيم -سوبسترا كميلكس سستى است. قبلاً كفتـه مسى شـد بسـته بـه اينكه سوبسـتر ا جقدر آسان اكسيد شود سرعت واكنش براكسيدازى بيشتر مىشود 
2016; Keyhani et al., 2005 (Khavari-Nejad, 2015)

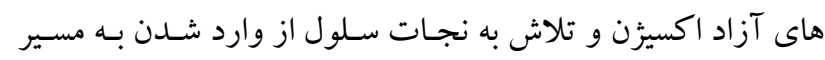

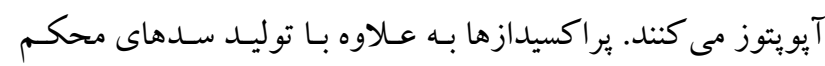

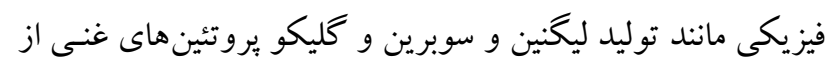

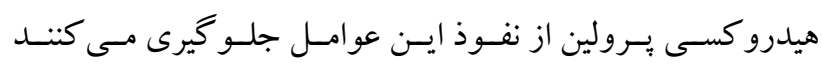

.(Bowles, 1990)

كاربرد ير اكسيدازها

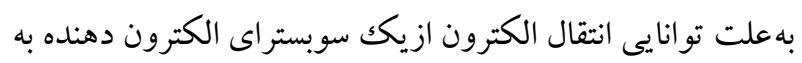

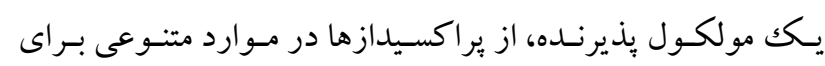

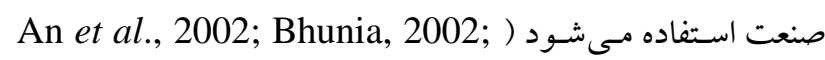
Shin \& Kim, 1998

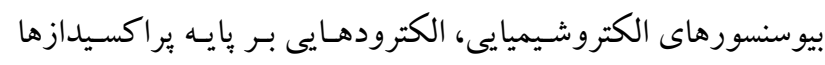

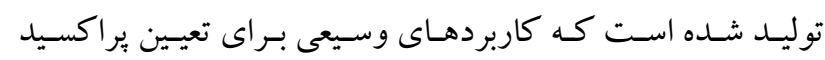
هيدروزن و هيدروير اكسيدهاى آلى در سيستم هاى آناليتيك دارند

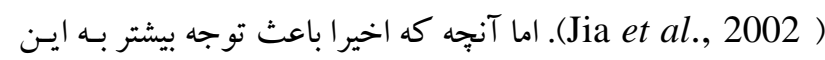

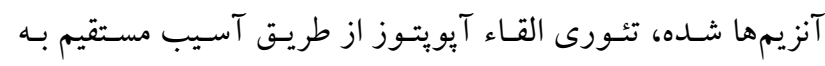
آنزيمهاى حياتى سلول است ( Attar et al., 2009; Hadizadeh (et al., 2009; Khavari-Nejad \& Attar, 2015 هورس راديش ير اكسيدازC نوتركيب، كه فاقد بخشهـاى حجيم

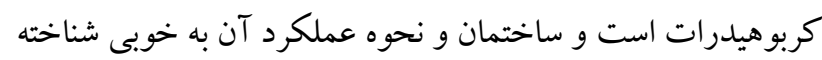

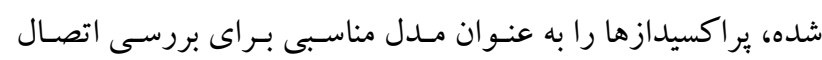

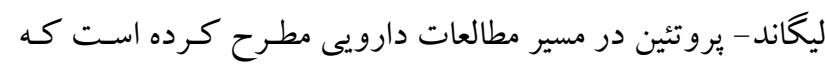

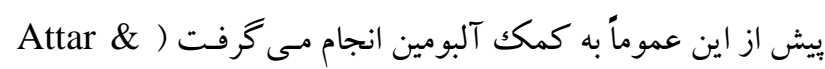
Khavari-Nejad, 2016; Keyhani et al., 2003; Tayefi.(Nasrabadi et al., 2006

\section{روش هاى متداول آزمايشكاهى براى مطالعه عملكرد و ساختار}

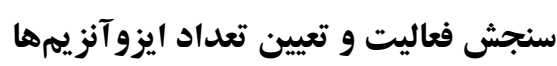

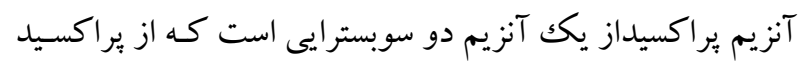

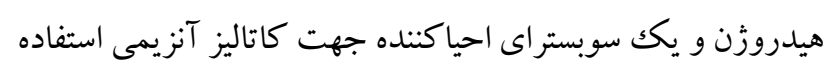

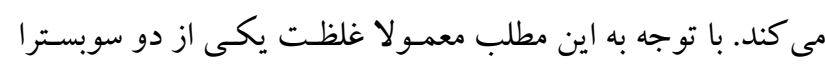

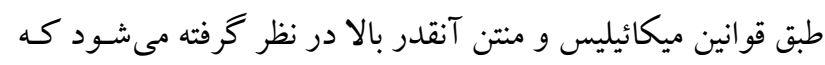

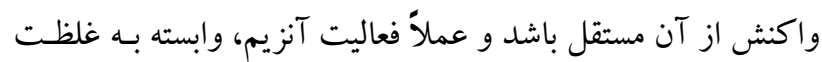

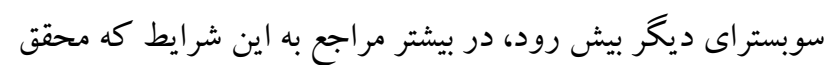

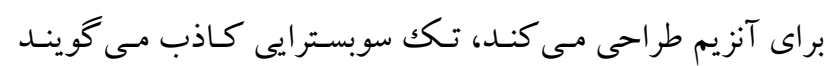

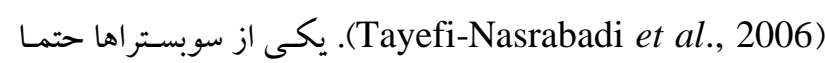

ماده لازمه اتصالات عرضى گروههاى فنلى است و بـا ايـن كار در طويل شدن سلول نقش دارند (Welinder, 1979).

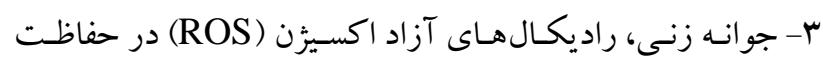

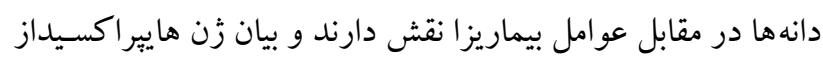

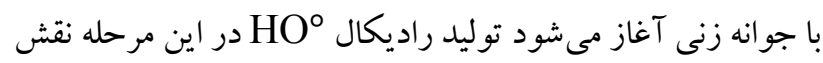

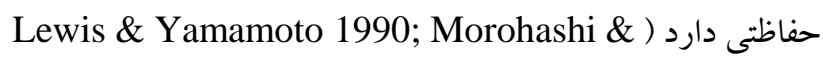
.(Matsushima, 2000; Wu, 2001 F- F تشكيل ليكنين و سوبرين، جفت شدن اكسيداتيو زيرواحـدهاى

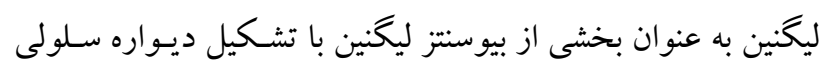

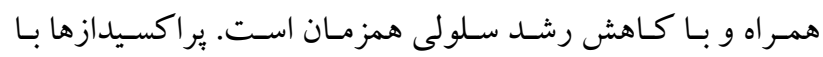

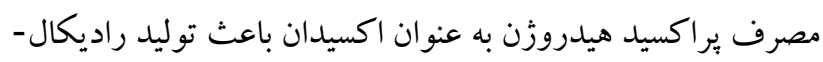

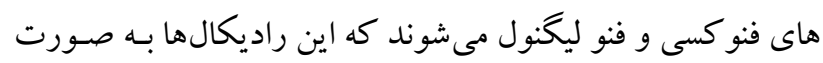

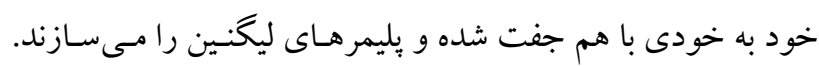
ازسوى ديخر اتصال عرضى منومرهاى فنلى باعثث توليـد سوبرين مى شود (Alexander \& Grierson, 2002). ه- رشد و رسيدن ميوهها، رشد ميوه با بزر گكى شـدن سـلول همـراه

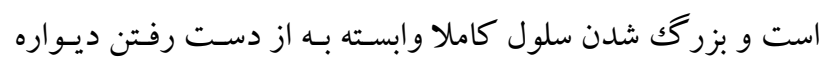

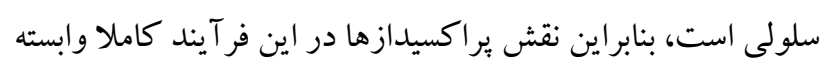

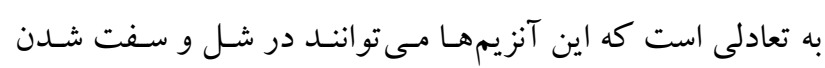
ديواره سـلول كيـاهى برقرار كنتــ ) Alexander \& Grierson, (2002 9- باسخ به تنشها، توليد راديكالهاى آزاد اكسيزن (ROS) يكك

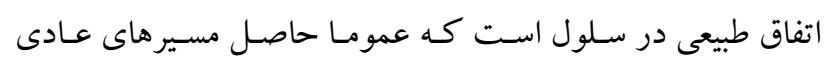
متابوليكك از جمله تنفس و اكسيد شدن مولكولهها است. امـا ميزان توليد اين تركيبات تحت تنشهاى محيطى افزايش مسي يابـد، ايـن

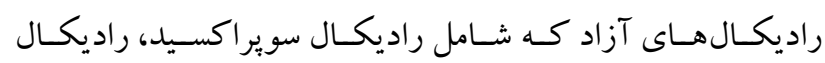
هيدرو كسيل، به علاوه مشتقات اكسيزّن با الكترونهاى نـابر ابر مثل ردئل

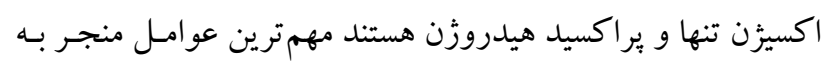

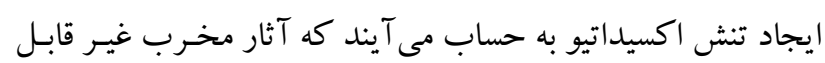

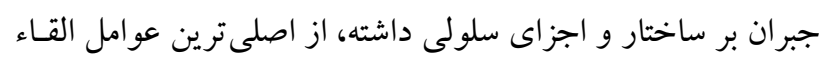

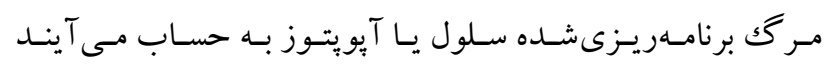
Khavari-Nejad, 2015; Khavari-Nejad et al 2007; ) (Keyhani et al., 2009

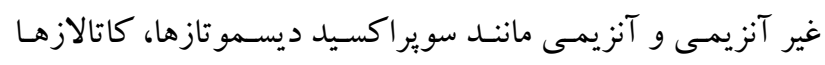
Khavari-Nejad et al., 2007; Khavari-Nejad et al., ) 
تغييرات محيط اطراف هم باعث تغيير در جـذب الكترونى آنزيم

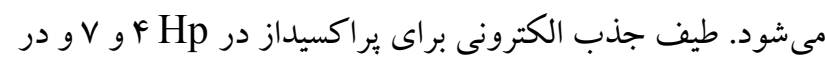

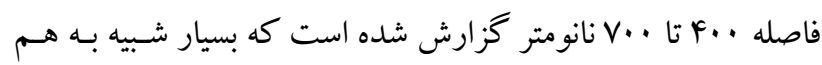
هستند ) Khavari-Nejad \& Attar, 2015; Lourenti et al., 2000; Smulevich et al., 1997

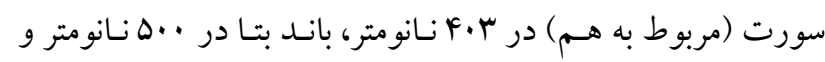

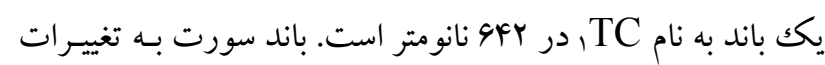

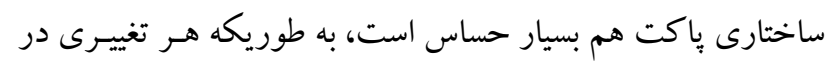

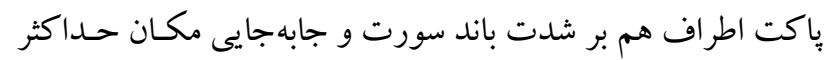

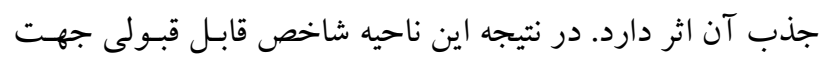

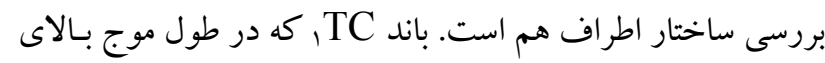

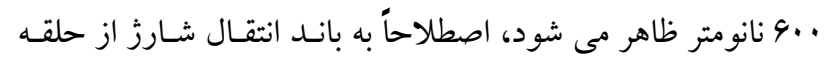

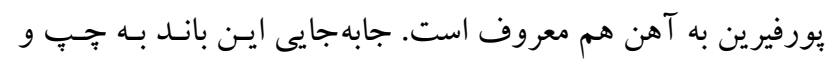

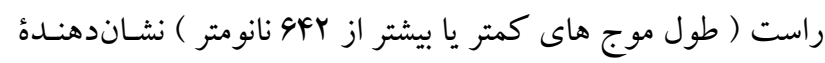

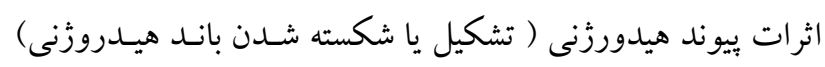

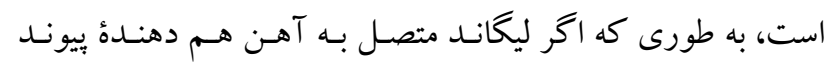

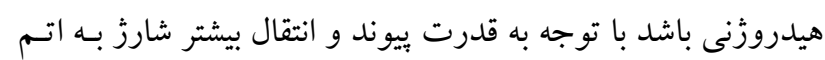

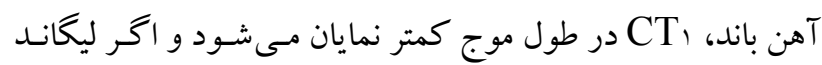

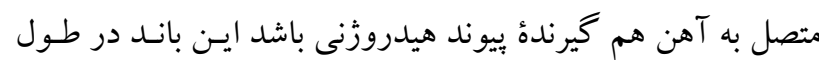

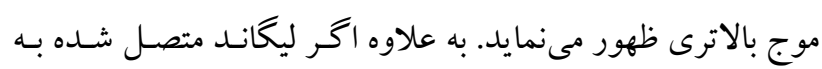

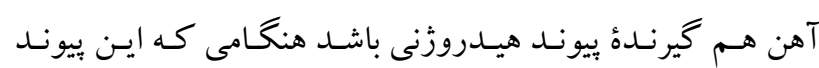

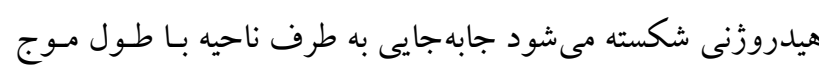

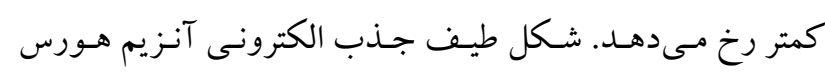

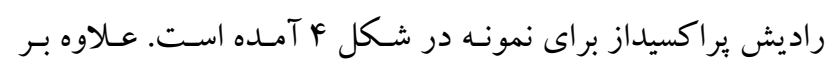

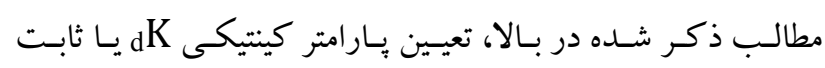

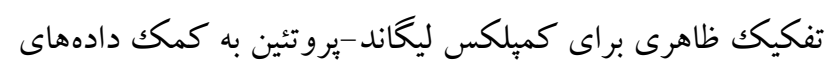

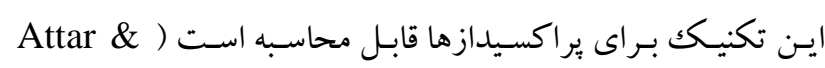
Khavari-Nejad, 2016; Khavari-Nejad \& Attar, .(2015

\section{بروسى تغييرات ساختارى ثراكسـيدازها بـا اسـتفاده از طيـف}

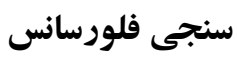

ير اكسيدازها به علت داشتن رزيدوهاى تـايروزين و ترييتوفـان در

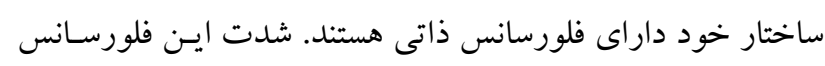

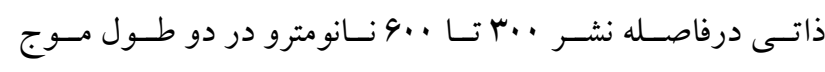

ير اكسيد هيدروزن است كه معمولا به صورت روزانه در آزمايشكاه

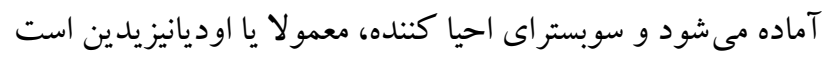
Khavari-Nejad \& Attar, 2015; Keyhani et al., 2003;) Rahmani, ) ويـا كاياكل (Tayefi-Nasrabadi et al., 2006

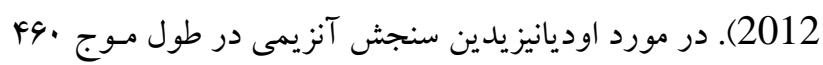

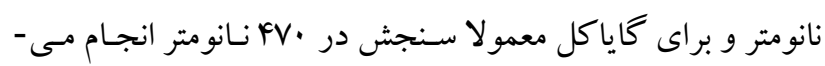
كيرد.

نظر بـه اينكـه ايزو آنزيمهــاى متعـددى از براكسيداز در مراحل

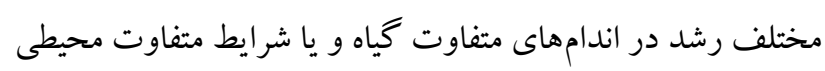

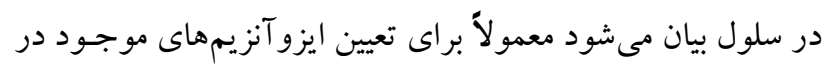

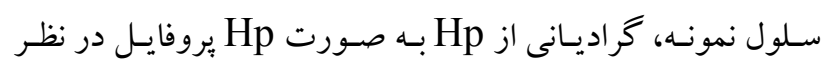

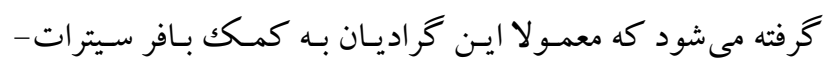

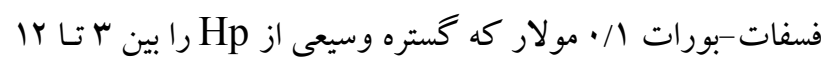

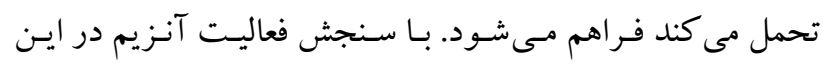

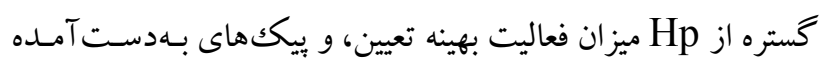

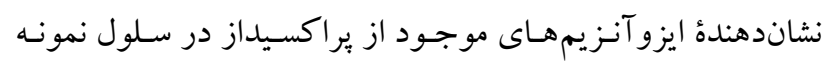

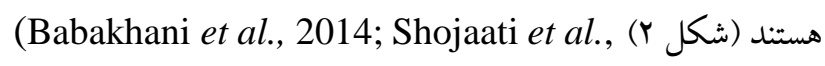
2015; Shams, 2014 در همين مرحله قابل محاسبه است. زل ألكتروفورز تأييد تعداد ايزو آنزيمهاى براكسيداز و يا آنزوز ايش و كاهش مقدار آنزيم درسلول نمونه به كمكك زل الكتروفورز امكـانيـذير اسـت.

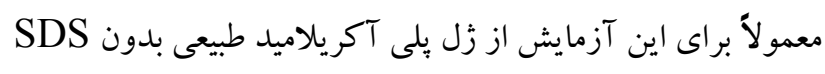

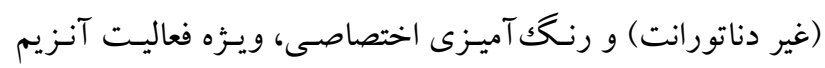

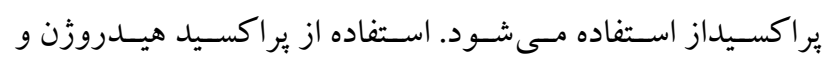

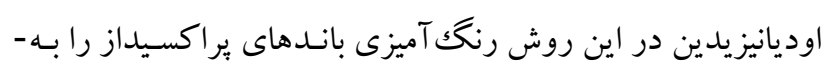

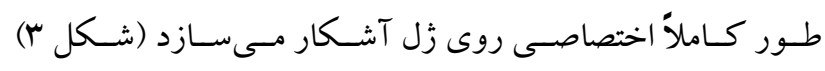

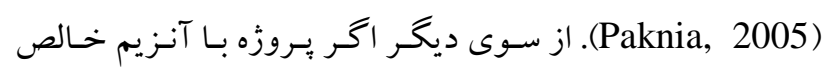

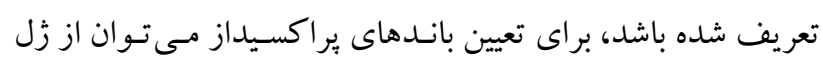
آكارز و رنغك آميزى با كوماسى بلو نيز استفاده كرد. برداي

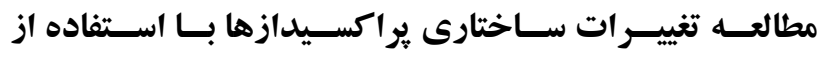

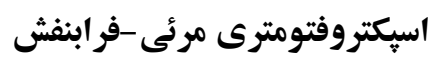

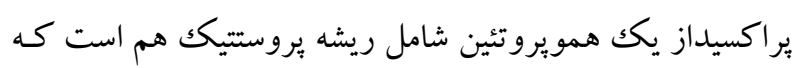

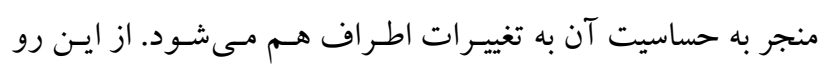




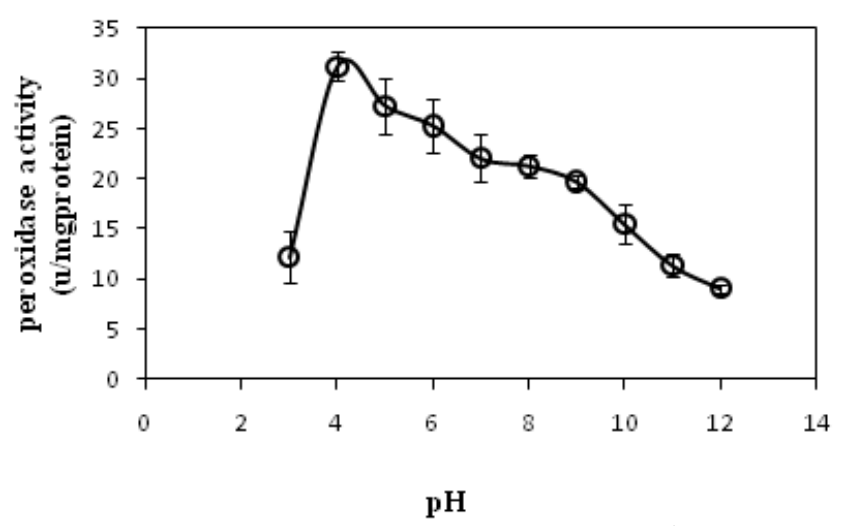

شكل r - منحنى pH بهينه فعاليت آنزيم ير اكسيداز در عصارمى آلوئهورا و در حضور سوبستراى ير اكسيد هيدروزن واوديانيز يدين (Shojaati, 2015).

Fig. 2. The pH profile of peroxidase activity in Aloe vera L. extracts assayed with Hydrogen peroxide and O-dianisidine (Shojaati, 2015).

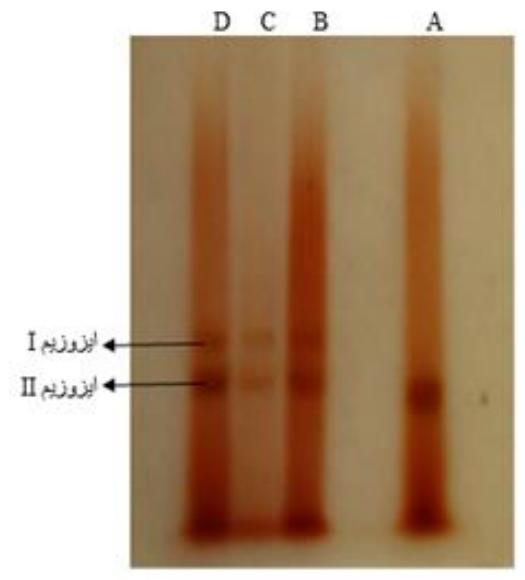

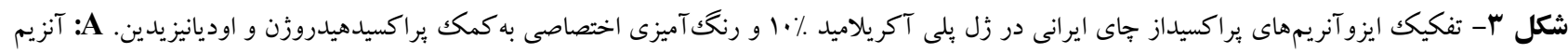

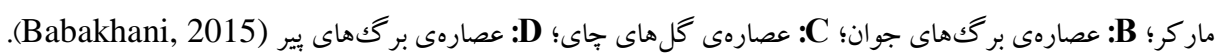

Fig. 3. Peroxidase isoenzymes in Camellia Sinensis differentiated with polyacrilamide gel $10 \%$ using $\mathrm{H}_{2} \mathrm{O}_{2}$ and $\mathrm{O}-$ dianisidine. A: marker; B: young leaves extract; C: flowers extract; D: old leaves extracts (Babakhani, 2015).

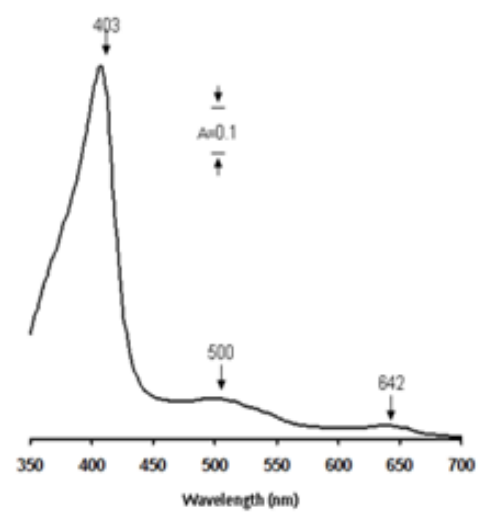

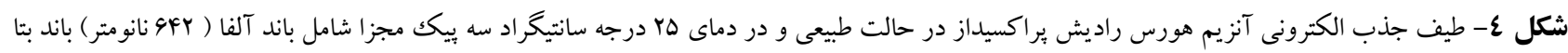

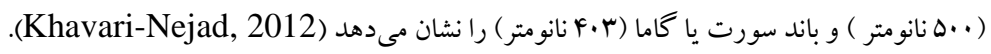

Fig. 4. Electronic absorption spectra for peroxidase at room temperature showed three separate picks Alpha band $(642 \mathrm{~nm})$, beta band (500nm) and soret band (403nm) (Khavari-Nejad, 2012). 
تنش محيطى مى شوند. در اين ميان خـانو اده بـزر گك بر اكسـيدازها،

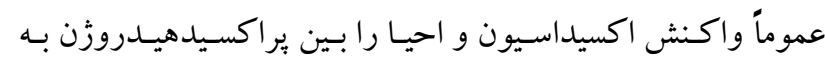

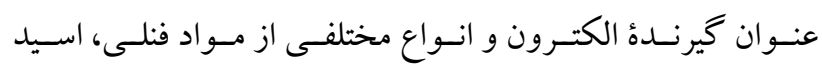
آسـكوربيكك و آمسينهـاى آروماتيـك كاتساليز مسى كنتسد. تبـديل ير اكسيد هيدروزن بـه مولكـول آب بـه وسـيله يراكسـيداز از توليـد

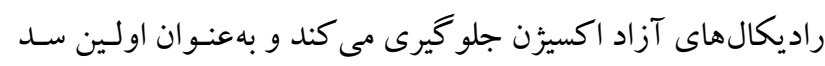
دفاعى سلول در برابر تنش اكسيداتيو بهحساب مى آيد. زمينه هاى مطالعه يراكسيدازها به عنوان اولين سد دفاعى سلول در برابر تنش اكسيداتيو تحميل شده از سوى عوامل محيطى در مسـير

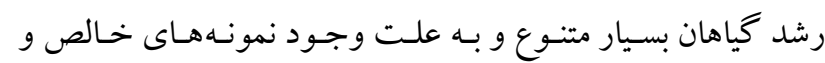
شناخته شدهاى مانند هورس راديسش براكسيداز در حسوزمى تغييـر

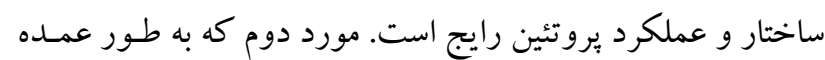
مديون موفقيت اسميت در توليد نوع نوتر كيب ايسن آنزيم در سـال 1990 است، بـه خصـوص باعـث نزديـكك تـر شـدن مرزهـاى علـوم كياهى و علوم سلولى و مولكولى به يكديخر شده، هر دوى آنها را به قلمرو علوم دارويى بيوند مى وهد.

\section{سياسگز ارى}

نغارنده از دكتر فرنوش عطار بابت كمكك هـاى نغارشى كمال

$$
\text { تشكر را دارد. }
$$

\section{REFERENCES}

Alexander, L. and Grierson, D. 2002. Ethylene biosynthesis and action in tomato a model for climacteric fruit ripening. - J. Exp. Bot. 53: 20392055.

An, S.Y., Min, S.K., Cha, I.H., Choi, Y.L., Cho, Y.S., Jin, C.H. and Lee, Y.C. 2002. Decolorization of triphenyl methane and azo dyes by citrobacter sp. - Biotechnol. Lett. 248:1037-1040.

Aslic, N., Akileswaran, L. and Gold, M.H. 1997. Characterization of the gene encoding manganese peroxidase isozyme 3 from Phanerochaete chrysosporium. - Biochim. Biophy. Acta 1338: 1-7.

Attar, F., Khavri-nejad, S., Keyhani, J. and Keyhani, E. 2009. Structural and functional alteration of catalase induced by acriflavine, a compound causing apoptosis and necrosis. - Ann. N.Y. Acad. Sci. 1171: 292-299.

Attar, F. and Khavari-Nejad, S. 2016. In vitro study of drug-protein interaction using electronic absorption, fluorescence, and circular dichroism spectroscopy. Arch Razi Inst. 71. 3: 183-194.

Babakhani, F. 2015. Study of catalase and peroxidase enzymes in young, old and tea plants. Department of Science and Research, Islamic Azad University, Master's Thesis.

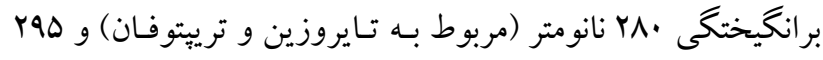
Khavari- (انومتر .(Nejad \& Attar, 2015; Tayefi-Nasrabadi et al., 2006 به اين ترتيب طيف نشرى يراكسيداز از تغييرات ساختارى مولكول

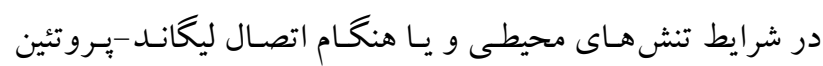

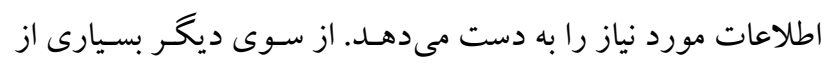

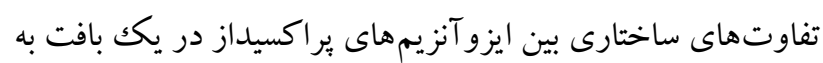
اين ترتيب قابل رديابى اسـت. تعيسين نسوع خاموشى فلورسـانس بـا روش استرن-ولمر كه نحوه خاموشى ماده فلوئوروفور در مجاورت

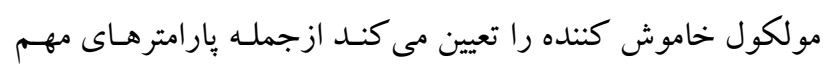
قابل اندازه گيرى در بروزههاى ليخاند-يـروتئين بـراى بر اكسـيدازها است كه با اين روش قابل دست يابى مىشود. يراكسيدازها و دورنتك نمايیى دورانى براى يراكسيدازها نيز مانند بسيارى از يـرو تئين هـا امكـان مطالعـه

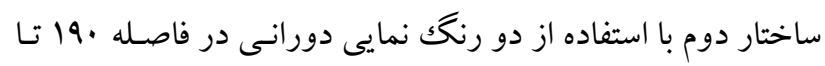
• Y نانومتر كه ناحيه جذب بيوند يِيتدى است وجود دارد. تخمين درصد هر جزء از سـاختمان دوم يـروتئين در براكسيداز عـلاوه بـر

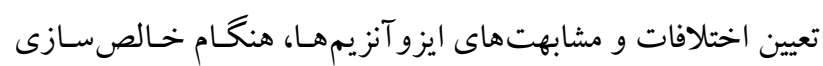
آنهـا نيـز بـراى تخمـين ميـزان خلــوص نمونسه و مطالعسه جزئيسات ساختارى بروتئين مورد استفاده است (Kelly \& Price, 2000).

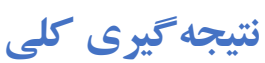

به طور كلى آنتى اكسيدانها مولكـول هـايى هستـند كـه بـا انتقـال

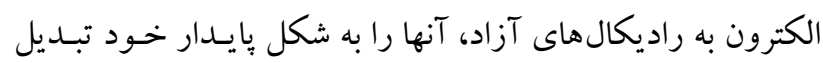

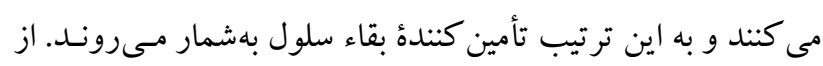
طرفى توليــ راديكـال هـاى آزاد بـه خصـوص راديكـالهــاى آزاد اكسيزّن در مسير هاى متابوليكك سـلول موضـوعى اجتنـابنايـذير و طبيعى است اما تـأثير تسنش هـاى محيطى بـر رشـــ و نمـو، سـاختار يرو تئين ها، تنفس و متابوليسم سلول سبب افزايش كونـهــاى فعـال

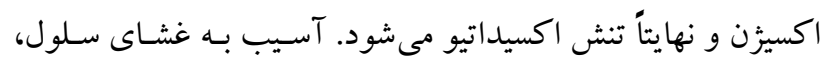

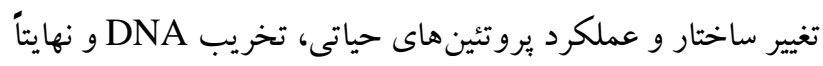
آغاز مسير مرگك برنامهريزى شده سلول اتفاقاتى هستند كه در ادامه تنش اكسيداتيو در سلول رخ مىدهند. اولين واكنش دفاعى سـلول در برابر تنش اكسيداتيو، افزايش ميزان فعاليتهاى آنتى اكسيداتيو و آنتى اكسيدانها است كه نهايتاً منجر به افزايش تحمل كياه نسبت به إنه 
Babakhani, F., Khavari-Nejad, S. and Eydi, A. 2014. Investigating activity of catalase in young, old and tea leaves. - The first international conference and the 4th National Conference on Medicinal Plants and Sustainable Agriculture. Hamedan. Iran.

Banci, L., Bertini, I., Turano, P., Tien, M. and Kirk, T.K. 1991. Proton NMR investigation into the basic for the relatively high redox potential of lignin peroxidase. Proc. Natl. Acad. Sci. U.S.A. 88: 6956-6960.

Baunsgard, L., Dalboqe, H., Houen, G., Rasmussen, E.M. and Welinder, K.G. 1993. Amino acid sequence of Coprinus macrorhizus peroxidase and DNA sequence encoding Coprinus cinereus peroxidase. A new family of fungal peroxidases. - Eur. J. Biochem. 213: 605-611.

Bhunia, A., Durani, S. and Wangikar, P. 2002. Horseradish peroxidase catalyzed degradation of industrially important dyes. - Biotechnol. Bioeng. 72: 562567.

Bowles, P.J. 1990. Defense - related proteins in higher plants. - Annu. Rev. Biochem 59: 873-907.

Candieas, L.P., Foles, L.K. and Wardma, P. 1997. Factors controlling the substrate specificity of peroxidases: kinetics and thermodynamics of the reaction of horseradish peroxidase compound I with phenols and indole-3- acetic acids. - Biochemistry 36: 7081-7085.

Candeias, L.P., Folks, L.K., Porssa, M., Parrich, J. and Wardman, P. 1996. Rates of reaction of indoleacetic acids with horseradish peroxidase compound I and their dependence on the redox potentials. Biochemistry 35: 102-108.

Chance, B., Sies, H. and Boveris, A. 1979. Hydroperoxide metabolism in mammalian organs. - Physiol Rev. 59: 527-605.

Chuang, W.J. and Van Wart, H.E. 1992. Resonance spectra of horseradish peroxidase and bovine liver catalase compound I Species. Evidence for predominant ZAZU Pi-cation radical ground state configuration. - J. Biol. Chem. 267: 13493-13301.

Cogrove, D.J. 2001. Wall structure and wall loosening. A look backwards and forwards. - Plant Physiol. 125: 131-134.

Conesa, A., Punt, P.J. and Van den Honder, A.M.J.J . 2002. Fungal peoxidases: Molecular aspects and applications. - J. Biotechnol. 93: 143-158.

Dunford, H.B. 1999. Heme peroxidase. - Plant Peroxidase Newsletter 13: 65-71.

Gajhede, M., Schuller, D.J., Henriksen, A., Smith, A.T. and Poulas, T.L. 1997. Crystal structure of horseradish peroxidase $\mathrm{C}$ at $2.15 \mathrm{~A}^{\circ}$ resolution. - J. Struct. Biol. 4: 1032-1038.

Gaspar, T.H., Pene, C. and Grapping, H.A. 1985. A twostep control of basic and acidic peroxidases and its significance for growth and development. - Physiol. Plant. 64: 418-423.

Hadizadeh, M., Keyhani, E., Keyhani, J. and Khodadadi, S. 2009. Functional and structural alterations induced by copper in xanthine oxidase. - Acta Biochim. Biophys. Sin. 41: 603-617.
Haschke, R.H. and Friedholff, J.M. 1978. Calciumrelated properties of horseradish peroxidase. Biochem. Biophy. Res. Communi. 80: 1039-1043.

Hayashi, Y. and Yamazaki, I. 1979. The oxidation reduction potentials of compound I/ compound II and compound II Ferric Couples of horseradish peroxidases Az and C. - J. Biol. Chem. 254: 9101-9106.

Hiraga, S., Sasaki, K., Ito, H., Ohashi, Y. and Matsui, H. 2001. A Large family of class III plant peroxidases. Plant Cell Physical. 42: 462-468.

Jia, J., Wong, B., Wu, A., Cheng, G., Li, Z. and Don, S. 2002. A method to construct a third-generation horseradish peroxidase biosensor: Self- assembling gold nanoparticles to three- dimensional sol-gel network. Anal. Chem. 74: 2217-2223.

Job, D. and Dunford, H.B. 1976. Substituent effect on the oxidation of phenols and aromatic amices by horseradish peroxidase compound I. - Eur. J. Biochem. 66: 607-614.

Kelly, Sh.M. and Price, N.C. 2000. The use of circular dichroism in the investigation of protein structure and function. - Curr Protein Pept. Sci. 1: 349-384.

Khavari-Nejad, S. r.Ir. Acriflavine- mediated apoptosis and necrosis in yeast Candida Utilis. Institute of Biochemistry and Biophysics Tehran University. PhD Thesis.

Khavari-Nejad, S. 2015. Doxorubicin-induced alterations in anti-ROS enzymes activity and cytochromes content in Candida utilis .- J. Pharm. Pharmacol. 3: 417-424.

Khavari-Nejad, S. and Attar, F. 2015. In Vitro Study of acriflavine interaction with horseradish peroxidase $\mathrm{C}$. - Biomacromolecular Journal 1: 130-139.

Khavari-Nejad, S., Keyhani, E. and Keyhani, J. 2007. Inhibition by Doxorubicine of anti-ROS enzymes superoxide dismutase and catalase in Salmonella typhymurium. - The $2^{\text {nd }}$ International Conference of BioMicroWorld, Seville, Spain.

Khavari-Nejad, S. Mashhadi akbar boojar, M. and Hejazi, A. 2016. Bufalin and digoxin induce apoptosis through ceramide and oxidative stress generation pathways in human melanoma cells. - Asian Academic Res. J. Multidisciplinary 3: 68-82.

Keyhani, E., Khavari-Njad, S., Keyhani, J. and Attar, F. 2009. Acriflavine-mediated apoptosis and necrosis in yeast Candida utilis. - Ann. N.Y. Acad. Sci. 1171: 284-291.

Keyhani, J., Keyhani, E., Eynollahi, N., Minai-Tehrani, D. and Zarchipour, S. 2003. Heterogeneous inhibition of horseradish peroxidase activity by cadmium. Biochim. Biophys. Acta. 1621: 140-148.

Keyhani, J., Keyhani, E., Khavari-Nejad, S., Attar, F. and Azzari, F. 2005. Combined effect of doxorubicin and metal on the yeast candida utilis. -BioMicro World $1^{\text {st }}$ International Conference, Spain, Badajoz.

Lewis, N.G. and Yamamoto, E. 1990. Lignin: Occurrence, biogenesis and biodegradation. - Annu. Rev. Plant Physiol. 41: 455-496.

Lourenti, E., Suriano, G. and Ghibaudi, R.P. 2000. Ionic Strength and $\mathrm{pH}$ effect on the Fe (III) imidazole bond in the heme pocket of horseradish peroxidase: an EPR 
and UV-Visible combined approach. - J. Inorg. Biochem. 81: 259-266.

Manjuanatha, B.R., Virupakshi, S. and Naik, G.R. 2003. Peroxidase isozyme polymorphism in popular sugarcane cultivars. - Curr. Science 85: 1347-1349.

Morohashi, Y. and Matsushima, H. 2000. Development of beta 1, 3- glucanase activity in germinated tomato seeds. - J. Exp. Bot. 51: 1381-1387.

Paknia, E. 2005. Investigation of the properties of peroxidase enzymes in Sardasht leaves. - Biochem. \& Biophysical Research Center, University of Tehran, Master's thesis.

Poulos, T.L., Freer, S.T., Alden, R.A., Edwards, S.L., Sogland, V., Takio, K., Eriksson, B., Xuong N.H., Yonetani, T. and Kraut, J. 1980. The crystal structure of cytochrome C peroxidase. - J. Biol. Chem. 255: 575-580.

Rahmani, A., Seyghali, N. and Ebrahimzadeh, H. 2012. Kinetic study of peroxidase activity in different concentrations of guaiacol in saffron crops. - Journal of Cellular-Molecular Biotechnology. Volume III, No. 11, 77-81.

Schuller, D.J., Ban, N., Huyste, R.B, Mcpherson, A. and Poulos, T.L. 1996. The crystal structure of peanut peroxidase. - Structure 4: 311-321.

Scialabba, A., Bellani, L.M. and Dell' Aquila, A. 2002. Effects of ageing on peroxidase activity and localization in radish seeds. - Eur. J. Histochem. 46: 351-358.

Shams, S., Khavari-Nejad, S. and Eydi, A. 2014. A review and comparison of some of the biochemical properties of catalase enzymes in rosemary plants in three live modes, after separation from stems and dry plants. - Second Scientific and Research Conference on Biology and Horticulture. Tehran, Iran.

Shojaati Samarin, L., Khavari-Nejad, S. and Eydi, A. 2015. Investigation of catalase activity in Aloe vera plant under salinity stress. - Second International Conference on Science and Technology. Istanbul.

Shojaati Samarin, L. 2015. Investigating the activity of catalase and peroxidase enzymes in Aloe vera plant under salt stress. - Department of Science and Research, Islamic Azad University, Master's Thesis.

Shin, K.S. and Kim, C.J. 1998. Decolorization of artificial dyes by peroxides from the white - rot fungus. Pleurouts ostreatus. - Biotech. Lett. 20: 569572.

Sivaraja, M., Gidin, D.B., Smith, M. and Hoffman, B.M 1989. Identification by ENDOR of Trp 191 as the free -radical site cytochrome C peroxidase compound ES. - Science 245: 738-740.

Smith, A.T., Sanatama, N., Dacey, S., Edwards, M., Bray, R.C., Thorneley, and Burke, J.F. 1990.
Expression of a synthetic gene for horseradish peroxidase $\mathrm{C}$ in Escherichia coli and folding and activation of the recombinant enzyme with $\mathrm{ca}^{+2}$ and heme. - J. Biol. Chem. 265: 13335-143343.

Smith, A.T. and Veitch, N.C. 1998. Substrate binding and catalysis in heme peroxidases. - Curr. Opin. Chem. Biol. 2: 269-278.

Smulevich, M., Paoli, G.D., Santics, A.R., Mantini, F. and M. Coletta. 1997. Spectroscopic evidence for a conformational transition in horseradish peroxidase at very low pH. - Biochemistry 36: 640-649.

Tayefi-Nasrabadi, H., Keyhani, E. and Keyhani, J. 2006. Conformational changes and activity alterations induced by nickel in horseradish peroxidase. Biochimie. 88: 1183-1197.

Tmas, J.W. and Welinder, K.G. 1998. Glycosylation and thermodynamic versus kinetics stability of horseradish peroxidase. - FEBS Letters 421: 234-236.

Valderrama, B., Ayala, M. and Vasques-Duhalt, R. 2002. Suicide inactivation of peroxidase and the challenge of engineering more robust enzymes. - Chem. Biol. 9: 555-565.

Veitch, N.C. 2004. Structural determination of plant peoxidase function. - Phytochem. Rev. 3: 3-18.

Veitch, N.C. and Smith, A.T. 2001. Horseradish peroxidase. - Adv. Inorg. Chem. 51: 107-162.

Welinder, K.G. and Gajhede, M. 1993. Structure and evolution of peroxides plant peroxidases: Biochemistry and Physiology. - University of Geneva, Geneva. pp. 35-42.

Welinder, K.G. 1979. Amino acid sequence studies of horseradish peroxdiase. Amino and carboxyl termini, cyanogen bromide and tryptic fragments, the complete sequence and some structural characteristics of horseradish peroxidase C. - European J. Biochem. 96: 483-502.

Wu, C.T. 2001. Class I beta -1, 3-glucanase and chitinase are expressed in thermicropylar endosperm of tomato seeds prior to radical emergence. - Plant Physiol. 126: 1299-1313.

XU, Y., and Van Hugstee, R.B. 1994. Association of calcium and calmodulin to peroxidase secretion. - J. Plant Physiol. 141: 141-146.

$$
* * * * *
$$

How to cite this article:

$$
\begin{aligned}
& \text { Khavari-Nejad, S. 2019. A review on plant } \\
& \text { peroxidases. - Nova Biol. Reperta 5: 428-437 }
\end{aligned}
$$

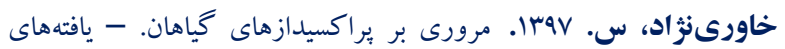

$$
\begin{aligned}
& \text { نوين در علوم زيستى ه: FYA-FYV. }
\end{aligned}
$$

